\title{
PRODUÇÃO DE CONHECIMENTO EM PRÁTICA AVALIATIVA DO PROFESSOR DE EDUCAÇÃO FÍSICA ESCOLAR: ANÁLISE DAS ESCOLHAS METODOLÓGICAS
}

\author{
Luciene Farias Melo \\ Universidade São Judas Tadeu, São Paulo, São Paulo, Brasil \\ Maria Luiza de Jesus Miranda \\ Universidade São Judas Tadeu, São Paulo, São Paulo, Brasil \\ Osvaldo Luiz Ferraz \\ Universidade de São Paulo, São Paulo, São Paulo, Brasil \\ Vilma Lení Nista-Piccolo \\ Universidade Federal do Triângulo Mineiro, Uberaba, Minas Gerais, Brasil
}

\begin{abstract}
Resumo
Neste estudo objetivou-se investigar a produção de conhecimentos sobre a prática avaliativa (PA) de professores de Educação Física (EF) publicada em artigos nas décadas de 1990 a 2010, analisando as escolhas metodológicas, como: a abordagem de pesquisa, o delineamento; os instrumentos e o tipo de população pesquisada. A amostra, composta por 18 artigos, foi coletada nas bases de dados SCIELO, SIBRADID e EBSCO-SPORT DISCUS. O trabalho inclui a descrição e a categorização dos dados expostos em tabelas, analisados com métodos quantitativos e qualitativos. Os resultados apontaram um restrito número de produções, verificou-se que o tema tem sido investigado sob a ótica qualitativa com predomínio de delineamento de pesquisa bibliográfica, apontando a PA do professor com poucas relações que abarquem a complexidade do processo de avaliação nas aulas de EF nos diferentes níveis do Ensino Básico.
\end{abstract}

Palavras-chave: Avaliação Educacional. Educação Física e Treinamento. Métodos.

\section{Introdução}

A partir de leituras sobre as pesquisas que abordam questões da avaliação do processo de ensino e aprendizagem na área da EF escolar, somadas aos debates sobre as tendências metodológicas, gerados numa disciplina de pós-graduação em nível de doutoramento, objetivou-se a construção deste estudo.

Nota-se que discutir o papel da escola no processo de avaliação do ensino e da aprendizagem dos alunos é tema de pesquisa que tem atraído alguns estudio- 
sos da área, como Maud (2003), Rodrigues (2003), Mendes, Nascimento e Mendes (2007), Melo (2008), Silva e Bankoff (2010) e Melo, Ferraz e Nista-Piccolo (2010).

Para Melo (2008) e Melo, Ferraz e Nista-Piccolo (2010) na escola a prática avaliativa deve permitir que as noções relativas ao processo de ensino, aprendizagem e avaliação sejam reelaboradas em um movimento dialógico entre a teoria e a prática. Além de favorecer a percepção de modificações na relação entre professor e alunos, com aumento da participação do docente e dos alunos durante a avaliação, tornando-se mais conscientes de suas responsabilidades diante da aprendizagem, da identificação das dificuldades dos alunos. Em síntese, a experiência avaliativa deve estar a serviço do processo de ensino e aprendizagem docente e discente.

No caso da Educação Física escolar, depara-se com discussões sobre as possibilidades de avaliar o processo de ensino e aprendizagem enfatizando uma proposta da avaliação realizada de maneira processual, vista como parte do processo educativo, tendo como finalidade a promoção das aprendizagens, do uso de diferentes espaços, tempos e instrumentos que possibilitem aos alunos um processo de ensino mais adequado (BRASIL, 1997, 1998, 2002; SOARES et. al., 1992). Vários autores argumentam que esses pressupostos apontam para a necessidade do professor de Educação Física escolar desenvolver uma avaliação qualitativa, que permita olhar de forma mais aprofundada para as manifestações de aprendizagem e das dificuldades dos discentes (FREIRE, 1989; FREIRE; SCAGLIA, 2004; MELO, 2008). Tenta-se, dessa forma, legitimar a presença da Educação Física na escola e, para tal, chega-se a afirmar que nesse componente curricular a prática avaliativa pode colaborar para melhorar o processo de ensino e aprendizagem dos estudantes.

Por outro lado, não faltam exemplos de que existe uma demanda de orientações aos professores de Educação Física a respeito do como executar a prática avaliativa em suas aulas com alunos do Ensino Básico. Nesse sentido, vários estudos afirmam as limitações no conhecimento dos professores da área, que avaliam apresentando restrito aprofundamento teórico e prático sobre as possibilidades de apreciar e valorar o ensino e as aprendizagens dos alunos (MENDES; NASCIMENTO; MENDES, 2007; SANTOS; GONÇALVEZ, 1996; SILVA; BANKOFF, 2010). Comumente, as pesquisas se deparam com respostas evasivas que denunciam pouco conhecimento sobre a escolha de critérios e de instrumentos de avaliação (SOUZA, 1993, 2010). Vários podem ser os causadores desses entendimentos limitados, como a necessidade de ampliar os estudos sobre o tema avaliação estabelecendo a coerência entre o processo avaliativo e os conteúdos, métodos de ensino e objetivos planejados (MELO, 2008; SOUZA, 1993); compreender a complexidade envolvida nas investigações sobre esse objeto de estudo; e ainda enten- 
der a forma como a produção de conhecimentos sobre o assunto têm sido realizada.

É importante enfatizar que investigar a prática avaliativa na escola envolve, portanto, a análise de temas diretamente relacionados, como a educação e a prática pedagógica como um todo (HADJ, 1994; LUCKESI, 2005; PERRENOUD, 1999). Nesse sentido, a compreensão sobre por quê, como e quando avaliar implica saber como são escolhidos os objetivos, os conteúdos e os métodos de ensino e como essas temáticas devem apresentar-se relacionadas, requer dos pesquisadores o uso de múltiplas lentes, vindas de diferentes áreas do conhecimento, como a psicologia e a pedagogia. Nesse sentido, os pesquisadores que se dedicam a analisar a prática avaliativa no ambiente específico das aulas de Educação Física têm como desafio inicial a escolha da perspectiva teórica e metodológica que será adotada para construir seus estudos.

A partir dessa escolha, um novo desafio se apresenta: organizar o planejamento da pesquisa a ser realizada, apresentando a natureza metodológica adotada, bem como o método e as técnicas a serem usadas na investigação. Com relação à natureza metodológica das pesquisas científicas, elas podem ser classificadas em três modalidades: a qualitativa, a quantitativa e a quanti e quali.

Em síntese, a pesquisa qualitativa se dedica à compreensão dos significados dos eventos, sem a necessidade de apoiar-se em informações estatísticas. $\mathrm{Na}$ pesquisa quantitativa, a base científica vem do positivismo, considerada como investigação objetiva que se baseia em variáveis mensuráveis e proposições prováveis. A pesquisa quanti e quali, como o próprio nome sugere, representa a combinação das duas modalidades citadas, utilizando em parte do trabalho a visão positivista, e em outra a visão fenomenológica, aproveitando-se do que há de melhor em cada uma delas (BOGDAN; BIKLEN, 1994; GIL, 2007). Concordando com Gil (2007), entende-se que métodos são um conjunto de procedimentos e instrumentos necessário à investigação científica. Eles são escolhidos pelo pesquisador para identificar e analisar os dados em investigações de campo, como a observação sistemática e estruturada, a observação participante, entrevistas, questionários e outras formas de coleta e análise. Enquanto que a metodologia resulta de um conjunto de procedimentos a serem utilizados pelo indivíduo na obtenção do conhecimento. É a aplicação do método, por meio de processos e técnicas, que garante a legitimidade do saber obtido por meio de descrições, explicações, e avaliações dos resultados encontrados (BOGDAN; BIKLEN, 1994).

A coerência entre a escolha do referencial teórico, da abordagem metodológica e do método empregado é fundamental para a qualidade da pesquisa realizada (GHEDIN; FRANCO, 2008). Assim, considerando a necessidade de que novos estudos sobre a prática avaliativa nas aulas de Educação Física sejam realizados (SANTOS, 2003), torna-se necessário identificar quais as escolhas têm sido 
feitas pelos pesquisadores que investigam a prática avaliativa nas aulas de Educação Física. A partir dessa identificação será possível observar se essas escolhas têm sido apropriadas para entender a complexidade do objeto avaliação do processo de ensino e aprendizagem em aulas de Educação Física escolar e sugerir novos aspectos considerados necessários para a construção de pesquisas sobre o tema.

Dessa maneira, neste estudo busca-se responder às seguintes questões: quais as abordagens metodológicas, delineamento das pesquisas; os instrumentos usados e o tipo de população têm sido escolhidos nas investigações sobre a prática avaliativa de professores de Educação Física no contexto escolar? A forma como essas pesquisas são realizadas permitem compreender o fenômeno de tamanha complexidade como a prática avaliativa levando em consideração as especificidades da área na escola?

Para responder essas perguntas o presente estudo tem como objetivo identificar aspectos que orientam as escolhas metodológicas, o delineamento das pesquisas; os instrumentos usados e o tipo de população adotados nos estudos realizados sobre a prática avaliativa realizada nas aulas de Educação Física, no período entre 1990 e 2010, já que como mostrado nos estudos de Santos $(2003$, 2005) e Alves e Soares Junior (2007) existem escassos estudos nessa área de conhecimentos que se dispuseram analisar as produções científicas veiculadas nas bases de dados com a intenção de realizar um mapeamento e conhecer tais estudos.

\section{Aspectos Metodológicos}

A análise da produção científica de determinada área de conhecimento é, segundo Witter et. al. (2007), um tipo de pesquisa que expressa a preocupação com o desenvolvimento da investigação e do conhecimento numa determinada área, como também evidencia o reflexo das pesquisas no uso social do conhecimento produzido em determinado contexto.

Para a construção deste tipo de pesquisa, os autores ressaltam a necessidade de se entender os pressupostos que orientam os trabalhos caracterizados como investigação da produção de conhecimento. Esses não devem ser classificados como estudos bibliográficos, que são desenvolvidos com a intenção de compreender determinado assunto, utilizando as informações disponíveis a partir de diferentes fontes, como os livros e as obras congêneres. A investigação da produção científica de uma determinada área de conhecimento deve levantar informações sobre o que está sendo realizado cientificamente sobre um determinado tema.

No âmbito da EF escolar, autores como Antunes et. al. (2005), Torres e Gaya (2006) e Pirolo et. al. (2007) citam que esse tipo de pesquisa tem sido realizada de maneira tímida nos vários contextos da área. Consideram que os pesquisa- 
dores têm dedicado pouca atenção aos estudos que se referenciam à prática pedagógica no contexto escolar, no qual se inclui o assunto avaliação do ensino e da aprendizagem. Mediante a escassez desse tipo de pesquisa, esta investigação busca compreender esse campo de estudos, identificando nas publicações dos periódicos da $\mathrm{EF}$ aspectos que se referem às escolhas metodológicas como: a abordagem, o delineamento das pesquisas; os instrumentos usados e o tipo de população mais investigada com relação ao tema prática avaliativa.

Para isso, neste estudo, foram elencadas as pesquisas publicadas em forma de artigos científicos. Escolha que se justifica por constituir parte importante da produção teórica da área da EF, mostrando-se um meio formal e preferencial dos pesquisadores para comunicarem e divulgarem seus estudos.

Inicialmente foram consultadas duas bases de dados, SCIELO e SIBRADID, que disponibilizam acesso gratuito. A pesquisa realizada nessas bases aconteceu com os seguintes descritores: avaliação, Educação Física; Educação Física escolar, avaliação da aprendizagem; evaluación del aprendizaje, educación fisica escolar; school physical education; assessment. Investigou-se também, por meio do acesso ao EBSCO, outra base de dados, a SPORT DISCUS, examinada utilizando-se dos mesmos descritores.

A decisão sobre a escolha das bases de dados SCIELO e SIBRADID fundamentou-se na observação da abrangência de periódicos nacionais e internacionais que elas oferecem e, também, por oferecerem mais estudos sobre o assunto investigado. Na caracterização dessas bases, tem-se na SCIELO uma atualização regular, o estabelecimento de parcerias com a Fundação de Amparo à Pesquisa do Estado de São Paulo (FAPESP) e o Centro Latino-Americano e do Caribe de Informação em Ciências da Saúde (BIREME), sem contar que disponibiliza as publicações de artigos científicos do Brasil e da América Latina. Na base SIBRADID (Sistema Brasileiro de Documentação e Informação Esportiva), existe com frequência a atualização da produção científica e é composta por artigos, dissertações e teses a respeito da área da EF e do Esporte no contexto brasileiro.

Com relação à SPORT DISCUS, essa base foi escolhida por apresentar-se especializada em periódicos que abordam assuntos sobre Esportes e EF, com atualização mensal, incluindo periódicos internacionais que apresentam boa diversidade de pesquisas que se remetem a EF escolar.

Partindo das observações sobre as bases de dados, os critérios de inclusão foram definidos com a escolha de estudos desenvolvidos no contexto da EF escolar e que apresentassem pesquisas sobre a prática de avaliação realizada pelo professor de EF em diferentes níveis do ensino básico (Educação Infantil, Ensino Fundamental e Ensino Médio).

Para a seleção dos artigos, foi percorrido um caminho longo e trabalhoso. Primeiramente, foi realizada uma varredura nas bases de dados mencionadas utili- 
zando-se dos descritores expostos acima. Neste momento foram encontradas algumas dificuldades para localizar os artigos específicos de acordo com o foco desta análise. Percebeu-se que as bases de dados demonstram uma escassez de possibilidades de combinações de descritores e, ao mesmo tempo, apresentam limitações nas opções de busca. Devido a esse obstáculo, gastou-se um enorme tempo para selecionar as produções que abordavam o tema pesquisado, já que a investigação foi feita manualmente. Foi necessário ler cerca de 2000 títulos e resumos disponibilizados pelas bases de dados por não oferecerem o recurso dos filtros de busca que poderiam facilitar o encontro dos artigos que atendessem os critérios definidos como inclusão. Foram descartados aqueles que abordavam a avaliação não contemplando o período escolhido ou o tema da investigação.

Após a etapa de seleção dos artigos, recorreu-se a mais uma leitura dos resumos dos artigos elencados. A partir disso foi feita mais uma triagem dos artigos, sobrando 150 resumos e textos que abordavam efetivamente o assunto avaliação em Educação Física escolar. Nesta etapa, foi possível perceber a insuficiência de informações oferecidas aos leitores nos resumos dos artigos, pois a maioria apresentam os objetivos e os resultados, e poucos apontavam subsídios satisfatórios que pudessem identificar o tipo de metodologia, os delineamentos da pesquisa, os instrumentos e o tipo de população investigada. Mediante esse problema, optou-se pela busca e leitura dos textos completos dos artigos que abordavam o tema avaliação em EF escolar, tendo em vista a realização da seleção final das produções que estavam estritamente relacionadas com a PA do professor de EF escolar, sendo, após esta etapa, a amostra reduzida para 18 artigos.

O passo seguinte foi a seleção das informações coletadas ordenando-as em tabelas conforme as categorias estabelecidas com base em Gil (2007), as quais estão expostas a seguir:

- $\quad$ Na categoria delineamento de pesquisa, foi observado se a pesquisa apresentava característica de pesquisa bibliográfica, documental, experimental, genuinamente experimental, pré-experimental, quase-experimental, ex-post-facto, levantamento surveys, estudo de caso, estudo de campo.

- No que se refere à categoria instrumentos de coleta de dados foram considerados os instrumentos de observação, entrevista, questionário aberto e/ou fechado, revisão sobre o assunto investigado publicada em livros e revistas da área; documentos das instituições de ensino investigadas e documentos públicos e oficiais.

- Finalmente, na categoria tipo de população foi buscada a característica dos indivíduos definidos para as pesquisas.

Para a construção desse estudo optou-se por apresentar as tabelas que descrevem a segunda redução dos dados construídas a partir das unidades de significados que mais se expressaram na análise dos artigos. Essas unidades de significa-

Pensar a Prática, Goiânia, v. 17, n. 1, p. 01-294, jan./mar. 2014 
do foram agrupadas nas categorias temáticas já expostas. Nas tabelas também são indicadas as porcentagens dos dados revelados em relação ao total de artigos investigados.

Seguindo esses pressupostos, o próximo item deste estudo apresenta a análise e a discussão dos dados que se utilizou de técnicas quantitativas e qualitativas, já que colaboravam com desvendamento de elementos importantes para a compreensão da problemática desta pesquisa, contribuindo para a compreensão do todo estudado (SUASSUNA, 2008).

\section{Análise e discussão dos dados}

Na Tabela 1 é apresentada de maneira sintética a seleção dos 18 artigos que se referiam, de maneira específica, à PA do professor de EF escolar, conforme está exposto:

Tabela 1: Detalhamento da busca dos artigos nas bases de dados

\begin{tabular}{|c|c|c|c|}
\hline Base de dados & $\begin{array}{l}N^{\circ} \text { de registros mos- } \\
\text { trados pelas bases }\end{array}$ & $\begin{array}{c}N^{\circ} \text { de registros de } \\
\text { acordo com os critérios } \\
\text { propostos }\end{array}$ & $\%$ \\
\hline SCIELO & 15 & $\begin{array}{c}\text { FILTROS } \\
\text { Somente texto completo } \\
\text { ou resumo } \\
1990-2010 \\
=\mathbf{0 2}\end{array}$ & $11 \%$ \\
\hline SIBRADID & 67 & $\begin{array}{c}\text { FILTROS } \\
\text { Somente resumos } \\
\begin{array}{c}1990-2010 \\
=\mathbf{1 1}\end{array}\end{array}$ & $61 \%$ \\
\hline $\begin{array}{c}\text { EBSCO - Sport Dis- } \\
\text { cus }\end{array}$ & 23 & $\begin{array}{c}\text { FILTROS } \\
\text { THESAURUS physical } \\
\text { education. } \\
\text { Somente texto completo } \\
\text { ou resumo } \\
\begin{array}{c}1997-2010 \\
=\mathbf{5}\end{array}\end{array}$ & $28 \%$ \\
\hline 3 bases & 105 & 18 & $100 \%$ \\
\hline
\end{tabular}

Ao considerar que neste estudo foi feito o recorte de duas décadas (de 1990 a 2010) para efetuar a investigação, nota-se que os 18 artigos selecionados representam um restrito número de produções que abordam, efetivamente, a PA do professor de EF.

Tal observação vem ao encontro do que Tavares (2003), Antunes et. al. (2005) e Pirolo et. al. (2007) se depararam em seus estudos sobre a escassez de 
pesquisas com temáticas que abarcam a EF como área de conhecimento no interior escolar, mais especificamente, nos trabalhos realizados no campo da intervenção pedagógica do professor, nos quais incluem as pesquisas sobre a PA.

Antunes et. al. (2005, p. 5), no estudo que buscaram retratar a pesquisa brasileira em EF escolar de 1999 a 2003, perceberam que:

Quando se analisa apenas as revistas generalistas, 76,2\% dos artigos não estão relacionados com a EF Escolar. Esses dados remetem a uma reflexão sobre a expansão do espaço ocupado pelas universidades. Possivelmente, esse resultado mostra as mudanças sofridas pela área que, no passado, era vista quase como sinônimo de EF Escolar, e hoje é considerada uma área mais abrangente que estuda o fenômeno movimento humano, desde o seu nível de análise bioquímico até o sociocultural.

Partindo da análise desses resultados os autores chegaram a constatação da EF escolar "não ser o objeto privilegiado de estudo [...]" para a área. Entende-se que esse quadro é considerado preocupante, pois "mostra um déficit de conhecimentos academicamente elaborados acerca da prática pedagógica na escola" (ANTUNES et. al., 2005, p. 5). Os autores levantam como possível causa para esse problema:

[...] o distanciamento das instituições de ensino superior do sistema básico de ensino. Quem está no cotidiano escolar não sabe o que os pesquisadores estão produzindo, e estes não sabem como aqueles profissionais atuam. (ANTUNES et al., 2005, p. 5).

No estudo de Job $(2010$, p. 4) são relacionados outros motivos para o baixo número de produções acadêmicas no âmbito da EF escolar, especialmente àquelas que se referem à prática de ensino e avaliação do professor da área. Segundo a autora, as revistas nacionais de EF sofrem com a questão das "edições irregulares, ausência de políticas editoriais claras, ausência de assinaturas e quase ausência de leitores". Como consequência, a materialidade social da produção científica da área é prejudicada, principalmente no que se refere à pesquisa realizada no e para o contexto escolar. Tais evidências levam a defender um maior investimento em pesquisas que possam contribuir para a melhora do processo de aprendizagem, do ensino e sobretudo do processo de avaliação realizado na EF escolar.

A leitura dos dados expostos na Tabela 1 também levou à observação de mais da metade do número de artigos $(\mathrm{n}=11)$ que abordam a PA na EF escolar pertencem à SIBRADID, representando $61 \%$ da amostra, com predomínio de publi- 
cações nacionais, diferente do que foi encontrado nas outras bases que ofereceram artigos internacionais.

No que diz respeito aos aspectos metodológicos, foram investigados nos artigos os tipos de delineamentos de pesquisas utilizados, que estão expostos a seguir:

Tabela 2: Análise dos artigos sobre a PA em EF escolar e respectiva porcentagem relacionada com a categoria delineamento das pesquisas.

\begin{tabular}{|c|c|c|}
\hline Delineamentos de pesquisa & $N^{\circ}$ de artigos & $\%$ \\
\hline Estudo de caso & 4 & 22 \\
\hline Estudo de campo & 3 & 17 \\
\hline $\begin{array}{l}\text { Descritiva por meio de levan- } \\
\text { tamentos (surveys) }\end{array}$ & 2 & 11 \\
\hline Bibliográfica & 5 & 28 \\
\hline Documental e bibliográfica & 3 & 17 \\
\hline $\begin{array}{l}\text { Descritiva (estudo compara- } \\
\text { tivo) }\end{array}$ & 1 & 5 \\
\hline TOTAL: $\quad 06$ tipos & 18 artigos & $100 \%$ \\
\hline
\end{tabular}

Quanto aos delineamentos metodológicos usados nos artigos investigados, percebe-se uma forte tendência para a utilização de delineamentos de pesquisas que abarcam o caráter qualitativo, apresentado em $28 \%$ da amostra de artigos que apontam para a utilização da pesquisa bibliográfica $(n=5)$. Essa constatação demonstra a presença de investigações produzidas por meio de discussões demasiadamente teóricas que objetivaram teorizar a PA dos professores de EF. Na sequência, verificaram-se os delineamentos que correspondem às características do estudo de caso, com $22 \%(\mathrm{n}=4)$, o estudo de campo, com $17 \%(\mathrm{n}=3)$ e o estudo documental combinado com a pesquisa bibliográfica, também com $17 \%(\mathrm{n}=3)$. Percebe-se que $55 \%$ de artigos $(\mathrm{n}=10)$, apenas denunciam as mazelas das práticas avaliativas cotidianas realizadas pelo professor de EF, pois o foco dos pesquisadores foi o de construir descrições sobre o que os professores sabem, como avaliam e quais as dificuldades encontradas, utilizando-se dos diferentes delineamentos de pesquisa mencionados, mas não apontam o que foi ou poderia ser feito para melhorar os problemas identificados nas práticas avaliativas dos professores investigadas. 
Santos (2005, p.17) considera que as pesquisas sobre a PA, realizadas por meio de delineamentos descritivos com sub-tipos que incluem o estudo de caso, de campo, documental e bibliográfico, representam baixo impacto no campo da ação pedagógica de avaliação na EF escolar. O mesmo autor assinala que:

[...] ao partir da reflexão de que na conjuntura posta nos estudos no campo da avaliação voltados para as constatações e denúncias já ofereceram sua parcela de contribuição, nos convida a realizar pesquisas que visem a investigar, analisar e divulgar as iniciativas de construção de práticas avaliativas comprometidas com a aprendizagem de todos os alunos e com o desenvolvimento dos professores e da escola.

A citação exposta ressalta a importância de se reconhecer o valor da pesquisa em PA na EF escolar com enfoque para investigações aplicadas in loco, já que a pesquisa descritiva, contribue pouco para a melhora da prática pedagógica de avaliação do docente da área.

$\mathrm{Na}$ tabela a seguir são apresentados os instrumentos de coleta de dados revelados nos artigos investigados, assinalando, mais uma vez, correspondência às pesquisas de caráter qualitativo que, segundo Gil (2007), usam diferentes técnicas de coleta de dados, derivadas das pesquisas nos campos da antropologia, psicologia e sociologia.

Tabela 3: Análise dos artigos sobre a PA em EF escolar e respectiva porcentagem, relacionados com a categoria utilização de instrumentos.

\begin{tabular}{|c|c|c|}
\hline Tipo de instrumentos & $N^{\circ}$ de artigos & $\%$ \\
\hline Registros da própria prática & 1 & 5,5 \\
\hline $\begin{array}{l}\text { Registros dos alunos, observa- } \\
\text { ção e diário de campo }\end{array}$ & 1 & 5,5 \\
\hline Livros e revistas da área. & 4 & 22 \\
\hline $\begin{array}{l}\text { Livros e revistas da área; docu- } \\
\text { mentos das instituições de ensi- } \\
\text { no investigadas e documentos } \\
\text { públicos e oficiais }\end{array}$ & 5 & 28 \\
\hline Questionário aberto e fechado & 1 & 5,5 \\
\hline Entrevista semiestruturada & 1 & 5,5 \\
\hline $\begin{array}{l}\text { Entrevista, Observação, Diário } \\
\text { de campo e fontes primárias } \\
\text { (doc. da escola) }\end{array}$ & 3 & 17 \\
\hline
\end{tabular}

Pensar a Prática, Goiânia, v. 17, n. 1, p. 01-294, jan./mar. 2014 
rias

TOTAL:

Verifica-se que os estudos que utilizam somente livros e revistas da área $(n=4)$ junto com os que combinam os levantamentos bibliográficos e documentais oficiais e das escolas que investigaram $(n=5)$, obtêm-se o percentual de $50 \%$ dos artigos investigados que se utilizaram desses instrumentos para a construção de suas investigações. Isso indica que valorizam discussões que buscam as "teorias de base", caracterizadas pela adoção de um quadro teórico emergido de levantamentos bibliográficos e documentais de diferentes naturezas.

Essa observação demonstra a tendência nos estudos sobre a PA na EF escolar, buscando um corpo teórico para fundamentar a temática avaliação. Considera-se relevante a produção desse tipo de conhecimento para a área, já que existe deficiência sobre o assunto avaliação, que colabore para a falta de conhecimento dos professores com relação ao ato de avaliar (MELO, 2008). Porém, o uso desses instrumentos para coleta de dados pautados somente em levantamentos bibliográficos e documentais, inevitavelmente apontam tendências de pesquisas que ficam presas no discurso teórico, não sendo suficientes para indicar possibilidades que viabilizem formas de processar a avaliação nas aulas de EF, levando em consideração especificidades e problemas que a área enfrenta na escola. Essa observação, mais uma vez, assinala a necessidade da produção de pesquisas que apresentem não só revisões teóricas ou apenas pesquisas descritivas, mas também proporcionem pesquisas aplicadas e relatos de experiências realizados no contexto escolar, apontando propostas que deram certo ou não circunscritas a partir da revisão de literatura pertinente ao assunto.

Por meio da Tabela 3 também é demonstrado que o segundo tipo de instrumento mais utilizado nos artigos $(\mathrm{n}=3)$ é a combinação de diversas ferramentas para a coleta de dados, como a entrevista, a observação, o diário de campo e as fontes primárias, representando $17 \%$ da amostra.

Essa constatação possibilita interpretar que o uso de diferentes instrumentos revela uma pequena parcela dos pesquisadores $(17 \%)$ considerando o que Ghedim e Franco (2008) denominam como multirreferencialidade no desenvolvimento de suas pesquisas, que significa a adoção da postura investigativa ponderando a complexidade do fenômeno investigado, por meio de múltiplos tipos de dados obtidos a partir da aplicação de diferentes instrumentos. Entende-se que isso colabora com a possibilidade do pesquisador produzir análises mais aprofundadas em âmbito educacional, adentrando na dinâmica e no significado dos dis- 
cursos, das práxis e registros dos sujeitos investigados. Para os autores essas ações permitem a compreensão das teorias implícitas que permeiam as ações do coletivo.

Entretanto, percebe-se uma maior porcentagem representada por $33 \%$ de artigos $(n=6)$ que mostram estudos com um ou dois instrumentos para coletar os dados sobre a PA do professor. Baseando-se nos autores supracitados, as pesquisas que coletam dados utilizando-se de poucos instrumentos, podem reduzir a investigação e a análise no campo educativo, não contemplam a complexidade e a dialética da realidade do fenômeno investigado.

Para finalizar a análise deste estudo, considerou-se relevante apreciar um último aspecto que diz respeito ao tipo de população usada na construção dos artigos investigados, pois esta informação auxilia o conhecimento sobre os níveis de ensino que os professores participantes das pesquisas sobre a PA em EF escolar atuam. Os dados estão expostos a seguir:

Tabela 4: Análise dos artigos sobre a PA em EF escolar e respectiva porcentagem, relacionados com a categoria tipo de população.

\begin{tabular}{lll} 
Tipo de população & $N^{\circ}$ de artigos & $\%$ \\
\hline $\begin{array}{l}\text { Professor-pesquisador do En- } \\
\text { sino Fundamental (2o ao 5o }\end{array}$ & 03 & $17 \%$ \\
anos) e alunos & $33 \%$ \\
$\begin{array}{l}\text { Professor de EF do Ensino } \\
\text { Fundamental (6 }{ }^{\circ} \text { ao } 9^{\circ} \text { anos) }\end{array}$ & \\
$\begin{array}{l}\text { Artigos que não usaram po- } \\
\text { pulação para o desenvolvi- } \\
\text { mento do estudo }\end{array}$ & $50 \%$ \\
\hline TOTAL: & $\mathbf{1 8}$ & $\mathbf{1 0 0 \%}$ \\
\hline
\end{tabular}

Os dados expostos nesta tabela explicitam que, dos 18 artigos analisados $50 \%$ referem-se às investigações que utilizaram professores da área para o desenvolvimento das pesquisas. Sendo assim, uma amostra de 33\% aponta para a escolha dos professores de EF que atuam nos anos finais do Ensino Fundamental. Na sequência, $17 \%$ de artigos usaram como população os professores dos primeiros anos do Ensino Fundamental.

Foi curioso notar que, nos artigos investigados, não se identificou estudos com professores de EF que atuam nos níveis da Educação Infantil e no Ensino Médio.

Desse modo ressalta-se a necessidade do desenvolvimento de estudos que envolvam os diferentes níveis de ensino da Educação Básica para possibilitar o desvelamento de peculiaridades de cada nível e contribuir com a construção de di- 
retrizes avaliativas contextualizadas visando promover mudanças nas ações de avaliar do professor de EF escolar de acordo com as característica de cada série.

\section{Considerações finais}

Neste estudo, embora a análise dos artigos tenha percorrido de maneira parcial o conhecimento produzido sobre a PA na EF escolar, foi possível identificar os ditos e os silêncios, as continuidades e as rupturas, os receios e as certezas, as permanências e mudanças no modo de pesquisar a avaliação na EF. O objeto de estudo apresentou-se com déficit de conhecimentos academicamente investigados em produções como os artigos científicos. Foram encontrados vários motivos na literatura que podem explicar tais observações. Os que mais se destacam são: o distanciamento dos pesquisadores das escola que compõem o sistema básico de ensino, produzindo pesquisas sem conhecer a realidade escolar. Aspecto que pode ser comprovado com o número de pesquisas dessa temática com restritas investigações que apresentem relatos de experiência de aplicação da PA em aulas de EF escolar.

$\mathrm{Na}$ análise dos aspectos metodológicos, percebeu-se significativo desenvolvimento da pesquisa qualitativa nos artigos analisados.

Nas escolhas metodológicas que envolvem os delineamentos, os instrumentos e a população investigada, foi possível perceber que embora fossem encontrados avanços no que se refere à literatura que discute a adequação dos métodos de pesquisas no contexto educacional observou-se um pequeno número de artigos que contemplou tais características, evidenciando, assim, a verificação de que a temática PA é uma área de estudos que apresenta um processo tímido de evolução na abordagem de pesquisa qualitativa, principalmente no que se refere à necessidade de abarcar com a complexidade dos fenômenos que envolvem o processo de avaliação nas aulas de EF escolar.

A forte inclinação para o delineamento de pesquisas de cunho bibliográfico e estudo de caso, corrobora a necessidade de valorizar investigações desenvolvidas por meio de pesquisas de campo, que possam oportunizar aos leitores a exposição de projetos, intervenções e relatos de experiências realizadas no contexto da EF escolar, visando oferecer conhecimentos sobre como ocorreu a aplicação da avaliação.

Considera-se também importante pontuar que durante a realização da pesquisa foram encontradas barreiras para o desenvolvimento da investigação sobre a produção de conhecimento em PA do professor de EF que podem dificultar o acesso dos profissionais da área nas bases de dados. Esses empecilhos evidenciam a necessidade de melhorar as bases de dados, além de uma avaliação mais criterio-

Pensar a Prática, Goiânia, v. 17, n. 1, p. 01-294, jan./mar. 2014 
sa nos periódicos anexados, solicitando maior cuidado com a elaboração dos resumos expostos nos artigos científicos.

Por fim, considera-se que, no momento histórico que a EF escolar vivencia, é imprescindível o investimento em pesquisas que abarquem com estes constitutivos, pois contribuem para a melhora do processo de aprendizagem e do ensino na EF escolar. Portanto, esse tipo de pesquisa requer a introdução do pesquisador na dinâmica e no significado dos discursos e da práxis docente para compreender, de maneira aprofundada, a representação singular da PA realizada em determinado contexto escolar, e a partir desse conhecimento, colaborar com a construção de diretrizes sobre o quê, como e por que avaliar o processo de ensino, aprendizagem nas aulas de Educação Física escolar.

\title{
PRODUCTION OF KNOWLEDGE IN ASSESSMENT PROCESS PHYSICAL EDUCATION TEACHER EDUCATION: ANALYSIS OF METHODOLOGICAL ELECTIONS
}

\begin{abstract}
This study aimed to investigate the production of knowledge about assessment practice (AP) teachers of Physical Education (PE) in articles published in the decades from 1990 to 2010, analyzing the methodological choices, such as the research approach, the design; the instruments and type of population studied. The sample consisted of 18 articles, was collected in databases SCIELO SIBRADID-SPORT DISCUS and EBSCO. The work includes the description and categorization of data in tables, graphs, analyzed quantitative and qualitative methods. The results showed a restricted number of productions, it was found that the subject has been investigated from the viewpoint with a predominance of qualitative research design literature, pointing to the AP teacher with a few relationships that encompass the complexity of the evaluation process in classes EF at different levels of basic education.
\end{abstract}

Keywords: Educational Measurement. Physical Education and Training. Methods.

\section{PRODUCCIÓN DE CONOCIMIENTO EN PRÁCTICA AVALIATIVA DEL PRO- FESOR DE EDUCACIÓN FÍSICA ESCOLAR: ANÁLISIS DE Las ELECCIONES METODOLÓGICAS}

\section{Resumen}

Este estudio tuvo como objetivo investigar la producción de conocimiento sobre las prácticas de evaluación (AP) profesores de Educación Física (PE) en artículos publicados en las décadas de 1990 a 2010, el análisis de las opciones metodológicas, tales como el enfoque de la investigación, el diseño; los instrumentos y el tipo de población estudiada. La muestra estuvo constituida por 18 artículos, fue recogida en las bases de datos SCIELO SIBRADID-SPORT DISCUS y EBSCO. El trabajo incluye la descripción y categoriza- 
ción de los datos en tablas, gráficos, analizar los métodos cuantitativos y cualitativos. Los resultados mostraron un número restringido de las producciones, se encontró que el tema ha sido investigado desde el punto de vista, con un predominio de la literatura cualitativa diseño de la investigación, señalando el maestro de AP, con algunas relaciones que abarcan la complejidad del proceso de evaluación en las clases EF en los diferentes niveles de educación básica.

Palabras clave: Evaluación Educacional, Educación y Entrenamiento Físico, Métodos.

\section{Referências}

ALVES, W. F.; SOARES JUNIOR, N. E. Educação Física escolar e a avaliação: análise dos trabalhos apresentados no GTT - escola no período de 1997 a 2005. In: CONGRESSO BRASILEIRO DE CIÊNCIAS DO ESPORTE, 15., 2007, Recife. Anais... Recife: [s. ed.], 2007. p. 01-08.

ANTUNES, F. H. C. et. al. Um retrato da pesquisa brasileira em Educação Física escolar: 1999 - 2003. Motriz, Rio Claro, v. 11 n. 3 p.179-184, set./dez., 2005.

BOGDAN, R.; BIKLEN, S. Investigação qualitativa em educação. Porto: Porto Editora, 1994.

BRASIL. Secretaria de Educação Fundamental. Parâmetros Curriculares Nacionais: Educação Física. Brasília: MEC/SEF, 1997.

. Ministério da Educação e Cultura. Secretaria de Educação Fundamental. Parâmetros Curriculares Nacionais, terceiro e quarto ciclos para o Ensino Básico: Educação Física. Brasília: MEC/SEF, 1998.

. Ministério da Educação e do Desporto. Secretaria do Ensino Médio. PCN mais. Brasília: MEC/SEF, 2002.

FREIRE, J. B. Educação de corpo inteiro: teoria e prática da Educação Física. São Paulo: Scipione, 1989.

FREIRE, J. B.; SCAGLIA A. J. Educação como prática corporal. São Paulo: Scipione, 2004.

GHEDIN, E.; FRANCO, M. A. S. Questões de método na construção da pesquisa em educação. São Paulo: Cortez, 2008. 
GIL, A. C. Métodos e técnicas de Pesquisa Social. São Paulo: Atlas, 2007.

HADJI, C. Avaliação regras do jogo. Porto: Porto Editora, 1994.

JOB, I. Avaliação de periódicos nacionais na área de Educação Física. Disponível em:

http://www.lume.ufrgs.br/bitstream/handle/10183/10691/000598933.pdf?

sequence $=1>$. Acesso: 15/09/2010.

LUCKESI, C. C. Avaliação da aprendizagem escolar: estudos e proposições. 16. ed. São Paulo: Cortez, 2005.

MAUD, J. Avaliação em Educação Física escolar: um relato de experiência. 2003. 69f. Dissertação (Mestrado em Educação Física Escolar)-Faculdade de Educação Física, Universidade Estadual de Campinas, Campinas, 2003.

MELO, L. F. O portfólio como uma possibilidade de intervenção pedagógica em Educação Física. 2008. 311 f. Dissertação (Mestrado em Pedagogia do movimento humano)-Escola de Educação Física e Esportes, Universidade de São Paulo, São Paulo, 2008.

MELO, L. F.; FERRAZ, O. L.; NISTA-PICCOLO, V. L. O portfólio como possibilidade de avaliação na Educação Física Escolar. Revista da Educação Física, Maringá, v. 21, n. 1, p. 87-97, jan./mar., 2010.

MENDES, E. H.; NASCIMENTO, J. V. do; MENDES, J. C. Metamorfoses na avaliação em Educação Física: da formação inicial à prática pedagógica escolar. Movimento, Porto Alegre, v. 13, n. 2, p. 55-76, maio/ago., 2007.

PERRENOUD, P. Avaliação: da excelência à regulação das aprendizagens - entre duas lógicas. Porto Alegre: Artes Médicas, 1999.

PIROLO, A. L. et. al. A produção do conhecimento em Educação Física escolar. In: CONGRESSO BRASILEIRO DE CIÊNCIAS DO ESPORTE, 15., 2007, Recife. Anais... Recife: [s. ed.], 2007. p.01-06.

RODRIGUES, G. M. A avaliação na Educação Física escolar: caminhos e contextos. Revista Mackenzie de Educação Física e Esporte, Barueri, v. 2, n.2, p. 1121, 2003.

Pensar a Prática, Goiânia, v. 17, n. 1, p. 01-294, jan./mar. 2014 267 
SANTOS, S. G.; GONÇALVES, G. A avaliação em Educação Física: uma análise nas escolas Estaduais e Municipais da cidade de Maringá. Revista da Educação Física, Maringá, v.7, n.1, p.75-83, 1996.

SANTOS, W. Avaliação na Educação Física Escolar: o Debate Acadêmico em Periódicos. In: ENCONTRO FLUMINENSE DE EDUCAÇÃO FÍSICA ESCOLAR, 7., 2003, Rio de Janeiro. Anais. Rio de Janeiro: [s. ed.], 2003. p. 1-17.

Avaliação na Educação Física escolar: do mergulho à intervenção. 2005. 125 f. Dissertação (Mestrado em Educação)-Faculdade de Educação, Universidade Federal de Minas Gerais, Belo Horizonte, 2005.

SANTOS, W. et. al. Avaliação na Educação Física escolar: o debate acadêmico em periódicos. Disponível em: <http://cev.org.br/biblioteca/avaliacao-educacaofisica-escolar-o-debate-academico-periodicos/>. Acesso: 22 janeiro 2009.

SILVA, J. F. da; BANKOFF, A. D. P. Métodos de avaliação em Educação Física no Ensino Básico. Conexões, Campinas, v. 08, n. 01, p. 54-76, jan./abr., 2010.

SOARES, C. L. et. al. Metodologia do ensino de Educação Física. São Paulo: Cortez, 1992.

SOUZA, N. M. P. de. Avaliação na Educação Física. In: VOTRE, S. (Org.). Ensino e avaliação em Educação Física. São Paulo: Ibrasa, 1993. p. 121-149

. Reflexões pedagógicas na avaliação em Educação Física escolar. In: PEREIRA, S. A. M.; SOUZA, G. M. C. Educação Física escolar: elementos para pensar a prática educacional. São Paulo: Phorte, 2010. p.111-124

SUASSUNA, L. Pesquisa qualitativa em Educação e Linguagem. Perspectiva, Florianópolis, v. 26, n. 1, p. 341-377, jan./jun., 2008.

TAVARES, O. Análise da Produção sobre a Educação Física na Revista Brasileira de Ciências do Esporte. In: CONGRESSO BRASILEIRO DE CIÊNCIAS DO ESPORTE, 13., 2003, Caxambu. Anais... Caxambu: [s. ed.], 2003. p. 01-09.

TORRES, L.; GAYA, A. A produção científica referenciada à Educação Física escolar do PPGCMH/UFRGS. Revista Brasileira de Educação Física e Esporte, São Paulo, v.20, n. 5, 2006. Suplemento

Pensar a Prática, Goiânia, v. 17, n. 1, p. 01-294, jan./mar. 2014 268 
WITTER, C. et. al. (Org.). Problemas Psicossociais: Análise de Produção. São Paulo: Guararema, 2007.

Recebido em: 05/06/2012

Revisado em: 10/11/2012

Aprovado em: 05/04/2013

Endereço para correspondência:

farias_luciene@yahoo.com.br

Luciene Farias Melo

Universidade São Judas Tadeu

Rua Taquari, 546 - Mooca,

Butantã, São Paulo - SP, 05503-000

Pensar a Prática, Goiânia, v. 17, n. 1, p. 01-294, jan./mar. 2014 